\title{
Activation of transcription factor AP-1 in response to thermal injury in rat small intestine and IEC- 6 cells
}

Yonghong Zhang ${ }^{1}$, Hong Zhao ${ }^{1}$, Tao Liu', Changrong Wan², Xiaoxi Liư ${ }^{1,2}$, Zhimin Gao ${ }^{1}$, Xiaolin Hou', Linshu Jiang ${ }^{1 *+}$ and Fenghua Liu ${ }^{1 *+}$

\begin{abstract}
Background: Our previous studies indicated that heat stress can cause significant damage to the intestinal epithelium and induce differential expression of many genes in rat small intestine. The transcription factors AP-1 and NF-KB, which act as important mediators by binding to specific DNA sequences within gene promoters, regulate the transcription of genes associated with immune regulation, stress response and cell fate.

Methods: To determine whether AP-1 and NF-KB are involved in hyperthermia-induced injury in rat small intestine and IEC-6 cells, we investigated their activity, and the expression of related proteins, by electrophoretic mobility shift assays and western blotting, respectively.

Results: Heat stress resulted in severe damage to the epithelium of the small intestine. The cell morphology and viability were obviously altered when IEC-6 cell was exposed to hyperthermia. AP-1 was activated in the small intestine of heat-stressed rats, as was phosphorylation of the JNK signaling pathway. In IEC-6 cell line, AP-1 activation in groups exposed to $42^{\circ} \mathrm{C}$ for $1 \mathrm{~h}, 2 \mathrm{~h}$ and $4 \mathrm{~h}$ was significantly increased. In contrast, NF-KB was not activated in both in vivo and in vitro models.
\end{abstract}

Conclusion: These results reveal that AP-1 is likely to play an important role in regulating gene transcription in rat small intestine and IEC-6 cells during exposure to heat stress.

Keywords: AP-1, NF-KB, Heat stress, Rat small intestine, IEC-6

\section{Background}

As one important physical stimulus, ambient temperature can evoke a series of drastic changes in biological function [1] including gastrointestinal injury and dysfunction [2]. Our previous studies have shown that heat stress can induce damage in the rat small intestine, along with differential expression of many genes associated with immune regulation and metabolism, and those encoding regulatory peptides [3]. A number of growth-related molecules (such as Gdf15, Gdf9, Ctgf, and Egfr) which are critical for cellular survival, proliferation and migration, have also been shown to be differentially expressed in response to hyperthermia-induced damage [4].

\footnotetext{
*Correspondence: jls@bac.edu.cn; Liufenghua1209@126.com

${ }^{\dagger}$ Equal contributors

${ }^{1}$ Beijing Key Laboratory for Dairy Cow Nutrition, Beijing University of Agriculture, No. 7, Beinong Road, Changping District, Beijing 102206, P. R. China
}

Full list of author information is available at the end of the article
Transcription factors, important mediators involved in signal transduction, bind to specific DNA sequences within gene promoters, and thus regulate transcriptional activity. Both NF-kB and AP-1 are well known pleiotropic transcription factors that independently and/or complementarily regulate a large number of genes related to a wide range of functions, including immune regulation, proliferation, differentiation, and apoptosis $[5,6]$.

NF- $\kappa B$ is a ubiquitous transcription factor and a member of a family of proteins that are important regulators of a variety of responses. NF- $\mathrm{KB}$ exists as a dimer predominantly composed of $\mathrm{p} 50$ and p65 subunits, although it also contains other family members, such as RelB, cRel, v-Rel and p52 [7]. The activity of NF- $\mathrm{kB}$ is regulated by a family of IкB inhibitor proteins [8], which sequester $\mathrm{NF}-\kappa \mathrm{B}$ in the cytoplasm. In response to various external pathogenic stimuli, IKB is phosphorylated, ubiquitinated, 
and subsequently degraded by a proteosome-dependent pathway. Degradation of IкB allows NF- $\mathrm{B}$ B to translocate into the nucleus, where it binds to specific promoter elements and induces gene transcription.

AP-1 is a central switch to convert extracellular signals into genetic responses and to determine cell proliferation, differentiation, and apoptosis. AP-1 complex consists of homodimers and heterodimers formed by a group of transcription factors, including members of the Jun, Fos, and ATF families [9]. Previous studies indicate that the c-Jun/ATF-2 heterodimer is one of the main components of expression pathways associated with oncogenesis [9] and the extreme cellular stress of ischemia and reperfusion [10]. JNK is one member of the mitogen-activated protein kinase (MAPK) family, which play crucial roles in many responses [11]. JNK was initially described as a stress-induced protein kinase acting to phosphorylate the $\mathrm{NH} 2$-terminus of the transcription factor c-Jun; hence, this pathway is often referred to as the stress-activated protein kinase (SAPK) pathway [12]. Multiple stresses increase JNK activity including UV, rirradiation, cytotoxic drugs, ischemia and reactive oxygen species. JNK phosphorylates several transcription factors including c-Jun, ATF-2, and p53 [13], which in turn regulate the expression of genes mediating cell proliferation, differentiation or apoptosis. Many studies have shown that there is crosstalk between JNK1 and NF-kB [14].

To further explore the mechanism of gene expression involved in hyperthermia-induced damage and repair in the rat small intestine, we investigated the activity of transcription factors AP-1and NF- $\mathrm{kB}$ and determined the expression of proteins acting upstream in their respective pathways, using both in vivo and in vitro models.

\section{Methods}

\section{Animals and treatments}

All protocols and procedures involving animals were approved by the Beijing University of Agriculture Institutional Animal Care and Use Committee, and conducted in accordance with the committee's guidelines. 12 male Sprague-Dawley (SD) rats weighing $200 \pm 20 \mathrm{~g}$ (obtained from Beijing Vital River Laboratory, Animal Technology Co., Beijing, China) were caged at $25{ }^{\circ} \mathrm{C}$, with a $12 \mathrm{~h}$ light:dark cycle and free access to food and water for 7 days. Rats were then randomly divided into control or heat-stress groups (6 rats per group) and housed in an artificial climate chamber (HPG-400BX, Harbin Donglian Electronic Technology, Heilongjiang, China) under normal conditions $\left(25{ }^{\circ} \mathrm{C}, 60 \%\right.$ relative humidity). Rats in the heat treatment group were exposed to $40{ }^{\circ} \mathrm{C}$ and $60 \% \mathrm{RH}$ from 11:00 to $13: 00$ for 3 consecutive days. The detail of heat-stress procedure was previously described by $\mathrm{Yu}$ et al. [4]. Rat rectal temperature was recorded daily before and after heat treatment using a thermistor probe connected to a digital thermometer. Body weight was recorded daily during the 7 adaptation days and the 3 treatment days.

\section{Sampling}

All rats were euthanized by decapitation without anesthesia immediately after the final $2 \mathrm{~h}$ heat treatment period. After euthanasia, trunk blood was collected and centrifuged at $3,000 \times \mathrm{g}$ for $10 \mathrm{~min}$ and the sera stored at $-20^{\circ} \mathrm{C}$ until required. Sections of the duodenum, jejunum and ileum were rapidly excised and washed with physiological saline. All intestinal segments were divided into two parts: 1) a section of $1 \mathrm{~cm}$ length was fixed in $10 \%$ neutral formalin for paraffin embedding; 2) a section of $3 \mathrm{~cm}$ length was minced and separated into three sample tubes, snap frozen in liquid nitrogen and stored at $-80{ }^{\circ} \mathrm{C}$ until required.

\section{Serum cortisol analysis and morphological examination}

Serum cortisol concentration was determined using an $\mathrm{I}^{125}$ cortisol radioimmunoassay kit, according to the manufacturer's instructions (Beijing Chemclin Biotech Co., Ltd, China). Formalin-fixed samples were embedded in paraffin and sectioned ( $5 \mu \mathrm{m}$ thick) in transverse orientation. After deparaffinization and dehydration, sections from the duodenum, jejunum and ileum were stained with hematoxylin and eosin. The structure of the mucosa was observed using an Olympus BH2 microscope (Olympus, Tokyo, Japan).

\section{Cell culture and treatments}

Rat IEC-6 cells (\#CRL21592, purchased from Peking Union Medical College, Beijing, China) were cultured in Dulbecco's modified Eagle medium containing 5 \% (v/v) fetal bovine serum (HyClone, Logan, UT, USA), $2 \mathrm{mg} / \mathrm{l}$ insulin, $50 \mathrm{IU} / \mathrm{ml}$ penicillin and $50 \mu \mathrm{g} / \mathrm{ml}$ streptomycin and incubated at $37{ }^{\circ} \mathrm{C}$ under $5 \%$ (v/v) $\mathrm{CO} 2$. The medium was replaced $24 \mathrm{~h}$ following initial cell plating. Control group cells were kept strictly at $37{ }^{\circ} \mathrm{C}$ under $5 \%$ $\mathrm{CO} 2$, while cells of the heat treatment groups were exposed to $42{ }^{\circ} \mathrm{C}$ under $5 \% \mathrm{CO} 2$ in the incubator (Thermo, Marietta, Ohio, USA) for $15 \mathrm{~min}, 30 \mathrm{~min} 1 \mathrm{~h}$, $2 \mathrm{~h}, 4 \mathrm{~h}$, and $8 \mathrm{~h}$, respectively. To inhibit specific intracellular agents, cells were pretreated with $10 \mu \mathrm{M}$ SP600125 (JNK inhibitor, \#1496, Tocris Bioscience, Bristol, UK) for $1 \mathrm{~h}$ prior to heat treatment. Changes in cell morphology following all treatments were observed using a phase-contrast inverted biological microscope (IX71/IX2, Olympus).

\section{MTT cell viability assay}

To measure cell viability, equivalent numbers of IEC-6 cells were plated on 96-well multiplates and cultured in DMEM containing $5 \%$ fetal bovine serum at a density of $1.2 \times 10^{5}$ cells $/ \mathrm{ml}$. After the cells were attached to the 


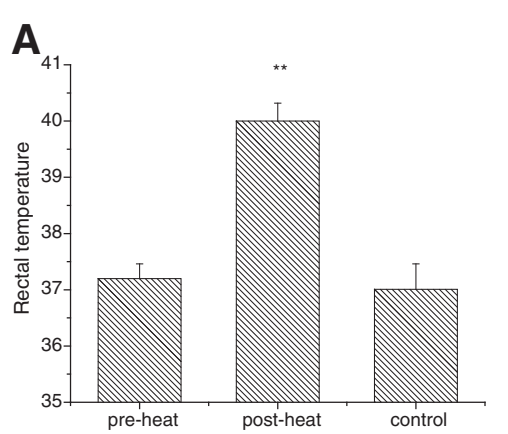

\section{B}

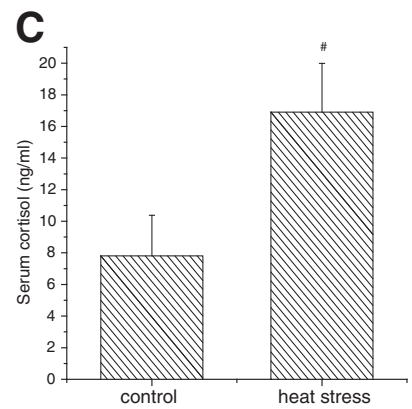

Fig. 1 Assessment of hyperthermia in an animal model. (a) Rat rectal temperature before and after heat treatment. Rat rectal temperatures were significantly elevated following $2 \mathrm{~h}$ heat exposure at $40{ }^{\circ} \mathrm{C}$. (b) Rat body weight before and after heat stress. Rat body weight was significantly decreased after heat treatment. (c) Mean cortisol concentration in the heat-stressed group was significantly higher than that of the control group. Values represent the mean \pm S.E. for $n=6$ rats per group. ${ }^{*} p<0.05,{ }^{* *} p<0.01$ indicate a significant difference for the rats before and after heat stress. \#p<0.01 indicates that the heat-stress group was significantly different from the control group

multiplate, control cells were maintained at $37{ }^{\circ} \mathrm{C}$, while heat-stressed cells were submitted to $42{ }^{\circ} \mathrm{C}$ for $15 \mathrm{~min}, 30 \mathrm{~min}, 1 \mathrm{~h}, 2 \mathrm{~h}, 4 \mathrm{~h}$, and $8 \mathrm{~h}$, respectively. Following the heat stress period, $10 \mu \mathrm{l}$ of MTT $(10 \mathrm{mg} / \mathrm{ml})$ was added to each well then incubated at $37{ }^{\circ} \mathrm{C}$ for $4 \mathrm{~h}$. Well media was aspirated and the formazan product dissolved using dimethyl sulphoxide. The remaining formazan product was analysed using a microplate reader (BIO-RAD, USA) at a fixed absorption wavelength of $570 \mathrm{~nm}$. Survival rates were calculated as percent OD570 of the untreated cells normalized to the 'zero' survival value.

\section{Protein extraction and measurement}

Nuclear and cytoplasmic extracts from rat small intestine and IEC-6 cells were prepared using the Nuclear and Cytoplasmic Extraction Reagent Kit (KeyGEN Biotech, Nanjing, China). Protein content was determined using the Pierce BCA protein assay kit (Thermo Fisher Scientific, Rockford, IL, USA) using bovine serum albumin as a standard.

\section{Electrophoretic mobility shift assay (EMSA)}

The nuclear fraction was used for EMSA analysis of AP1 and NF-kB. IRDye700-labeled AP-1 (sense: 5'-CGC TTG ATG ACT CAG CCG GAA-3'; antisense: 5'-TTC
CGG CTG AGT CAT CAA GCG-3') and NF- $k B$ (sense: 5'-AGT TGA GGG GAC TTT CCC AGG C-3'; antisense: 5'-GCC TGG GAA AGT CCC CTC AAC T-3') oligonucleotides were purchased from LI-COR Biosciences (Lincoln, NE, USA). Briefly, EMSA binding reactions were performed by incubating $2 \mu \mathrm{g}$ of nuclear extract with the annealed oligonucleotides and binding reagents for $30 \mathrm{~min}$ at room temperature in the dark. For the supershift assay, antibodies (Cell Signaling Technology, Inc., Danvers, MA, USA) were incubated with samples after the initial binding reaction between nuclear proteins and the oligonucleotides. The reaction mixture was subjected to electrophoresis on a $5 \%$ native gel at $4{ }^{\circ} \mathrm{C}$ in the dark. The gel was scanned using an Odyssey Infrared Imaging System (LI-COR Biosciences).

\section{Western blotting}

Twenty $\mu$ g of either cytoplasmic or nuclear lysate were resolved on a $12 \%$ polyacrylamide-sodium lauryl sulfate gel via electrophoresis and transferred to nitrocellulose membranes. After blocking, membranes were incubated overnight at $4{ }^{\circ} \mathrm{C}$ with respective primary antibodies (Cell Signaling Technology, Inc.) diluted to 1:1000. The blots were then incubated with a 1:15000 dilution of the antirabbit secondary antibody labeled with IRDye700 (LICOR Biosciences) at room temperature for approximately 


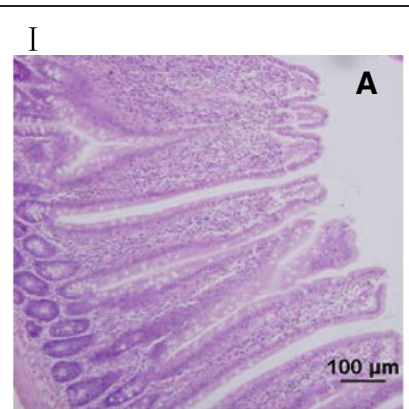

Duodenum

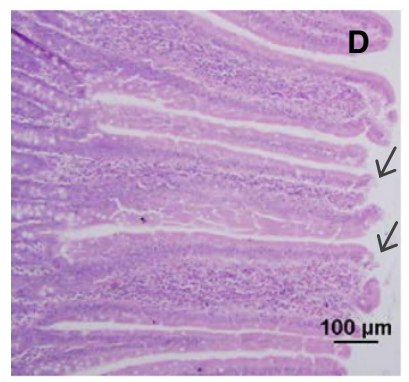

D

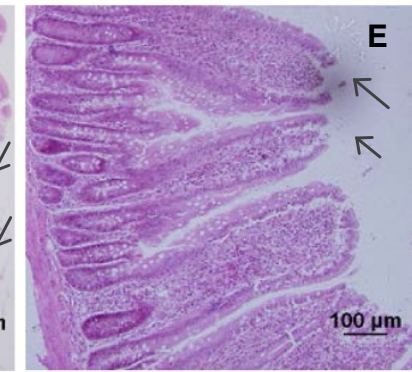

B

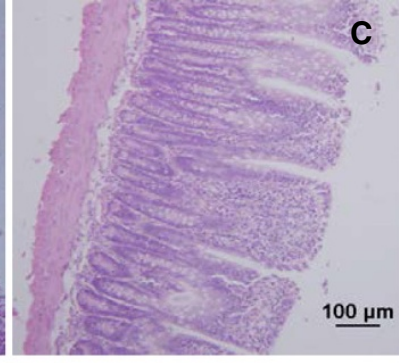

Ileum

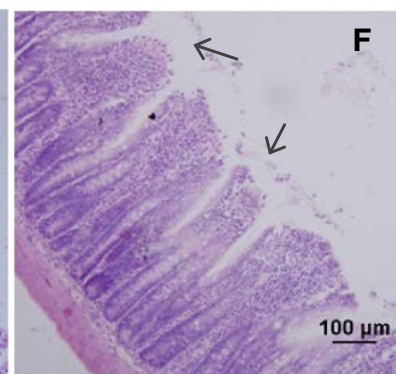

II

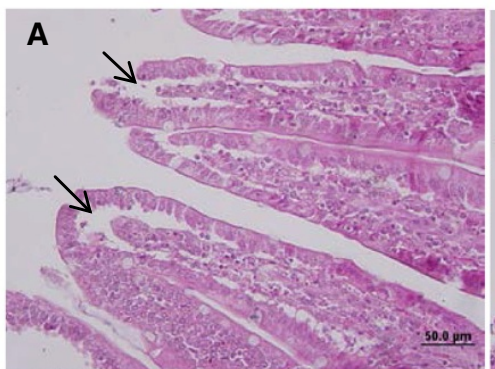

Duodenum heat

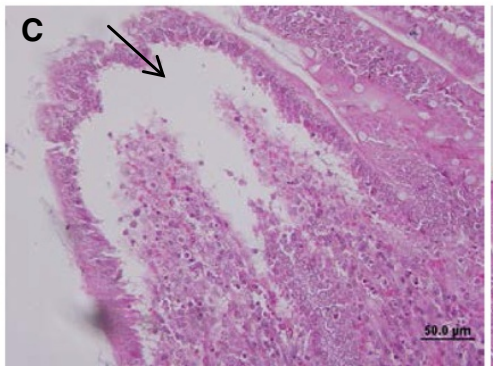

Ileum heat

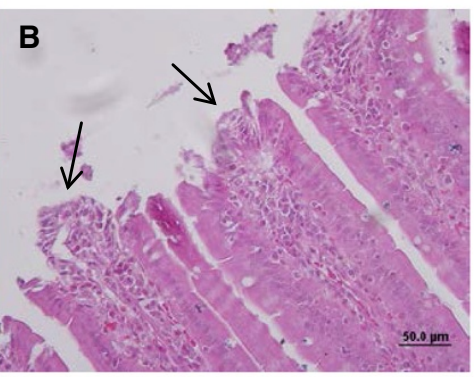

Jejunum heat

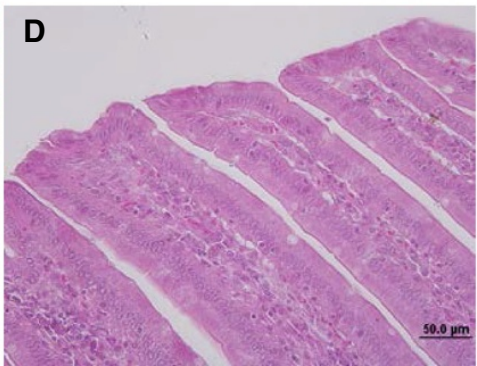

Control

Fig. 2 Morphology of rat small intestine in response to heat stress. (I) Photomicrographs of hematoxylin and eosin-stained sections of rat small intestine after 3 days of heat treatment. Upper panels show small intestine from control rats, lower panels show small intestine from heat-stressed rats. Thermal injury to the intestinal villi is apparent, with hyperemia desquamation at the tips of the intestinal villi. (II) Morphology of rat small intestine at higher magnification. Heat stress resulted in profound damage to the epithelium of the small intestine. Sloughing of epithelium off the basement membrane at the villus tips and even exposing of the lamina propria are more obvious at higher magnification. Abnormal microstructures are indicated by arrows

1-2 h. Finally, the membranes were scanned using an Odyssey Infrared Imaging System (LI-COR Biosciences).

\section{Statistical analysis}

Data analyses were carried out using SPSS12.0 (SPSS Inc., USA) and graphs were created using Origin6.0
(OriginLab, Northampton, USA). Differences between two groups were assessed using Student's $t$-test, or for more than two groups using an analysis of variance (ANOVA) combined with the post-hoc LSD test. Data are expressed as mean \pm S.E. Differences were considered statistically significant at $\mathrm{p}<0.05$. 


\section{Results and discussion}

Assessment of heat treatment in the animal model

In mammals, rectal temperature, serum cortisol level and body weight are used for a basic assessment of heat stress [15]. Fig. 1 summarizes these main characteristics. Compared with the results before heat stress, rectal temperature was significantly increased after treatment. Rat body weight was significantly decreased after heat treatment $(220.8 \pm 8.5 \mathrm{~g})$ compared with before treatment $(237.5 \pm 7.8 \mathrm{~g})$. There were no significant differences in either rectal temperature or body weight between the control group and the heat-stress group before treatment. Measurement of serum hormones showed that heat stress induced a significant increase in cortisol concentration compared with the control rats. These results are consistent with our previous reports $[4,16]$, in which the same model was used.

\section{Histological analysis}

Many environmental and biological stressors including radiation, hyperthermia (heat stress), LPS, various drugs, endotoxins, and ROS can cause significant damage to the intestinal epithelium [17]. In the case of hyperthermia, significant injury to the intestine is sustained

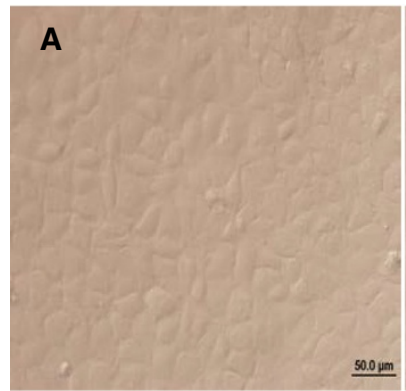

Oh

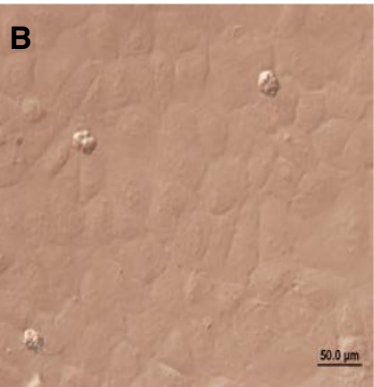

$2 \mathrm{~h}$

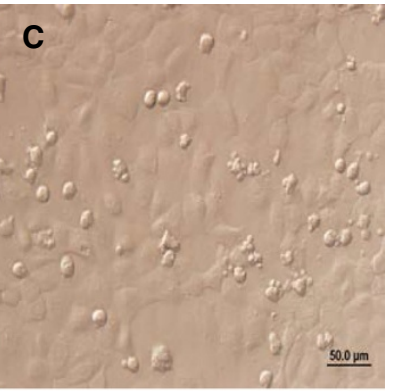

4h

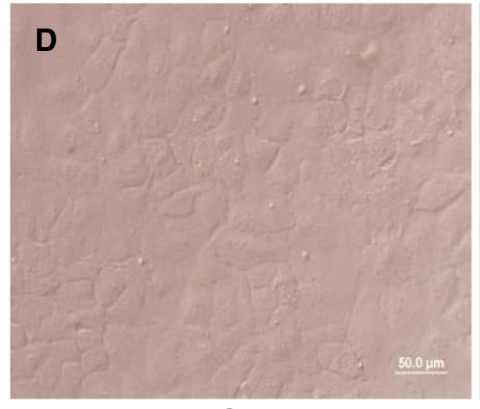

$2 h+S P 600125$

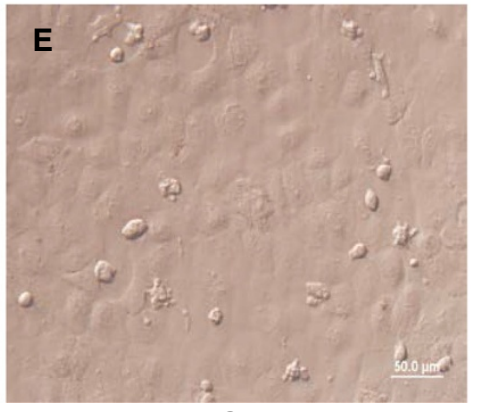

4h+SP600125

F

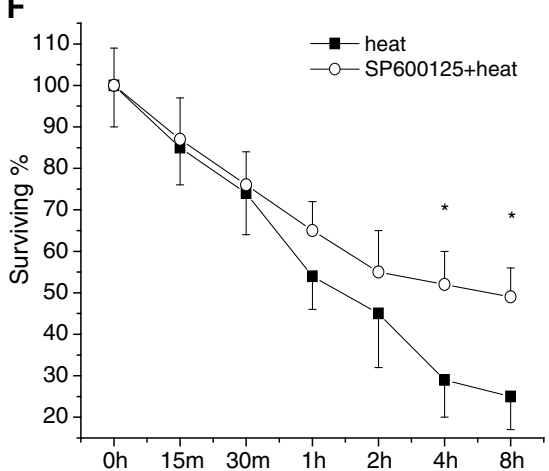

Fig. 3 Morphology and viability of IEC-6 cells in response to heat stress. Normal IEC-6 cells in control group (a). Cellular morphology was markedly altered following heat treatment $\left(42^{\circ} \mathrm{C}\right.$ for $4 \mathrm{~h}$ ), with changes in cell shape and a greater number of dead cells in the supernatant (b and $\left.\mathbf{c}\right)$. This effect was attenuated by pretreating cells with JNK inhibitor SP600125 (d and e). IEC-6 cell viability gradually decreased over time and SP600125 had a positive effect on cell viability (f). It was measured by MTT assay, in which IEC-6 survival rate was calculated as percent OD570 of the untreated group $\left(0\right.$ h). Data are mean \pm S.E., $n=3$ per treatment. ${ }^{*} p<0.05$, compared to respective heat-stress group 
because of reduced blood flow to the gut [2], resulting in ischemia within the small intestine [18]. Light micrographs of hematoxylin and eosin-stained small intestine tissue demonstrated that heat stress resulted in profound damage to the epithelium of the small intestine (Fig. 2I). Sloughing of epithelium off the basement membrane at the villus tips was observed in the heat-stressed tissue compared with the control tissue. Vacuolization of epithelial cells was also observed at higher magnification and, in severe cases, the lamina propria was exposed (Fig. 2II).

\section{Cell morphology and viability}

A previous report [19] indicated that the effect of heat treatment on IEC-6 cells was dependent on temperature and exposure time. According to methods used in our own previous study [4], IEC-6 cells were subjected to heat stress of $42{ }^{\circ} \mathrm{C}$. Following heat exposure, cells were examined under a phase-contrast inverted microscope. The morphology was markedly altered, with a different cell shape, and a greater dead cell mass was clearly observed in the supernatant after $4 \mathrm{~h}$ (Fig. 3C) of the cells being exposed to heat. In contrast, the damage was attenuated with addition of JNK inhibitor SP600125 (Fig. 3d and e). Compared to control cells, IEC-6 demonstrated $70 \%$ reduction of viability after $4 \mathrm{~h}$ at $42{ }^{\circ} \mathrm{C}$, whereas cells pretreated with SP600125 were relatively resistant to the toxic effect of heat (Fig. 3f).

\section{Effects of heat stress on AP-1 and JNK pathway}

EMSA assessment of AP-1 activation was performed in rat small intestine and IEC- 6 cells. Fig. 4 shows the results of representative experiments in vivo and in vitro. Compared with the control group, the activity of AP-1 in heat-stressed rats was increased (Fig. 4a). Following heat exposure, IEC- 6 cells were harvested at time $0 \mathrm{~h}$, then at $15 \mathrm{~min}, 30 \mathrm{~min}, 1 \mathrm{~h}, 2 \mathrm{~h}, 4 \mathrm{~h}$, and $8 \mathrm{~h}$. AP- 1 activation in groups treated for $1 \mathrm{~h}, 2 \mathrm{~h}$ and $4 \mathrm{~h}$ was significantly increased $(\mathrm{P}<0.05)$ compared to $0 \mathrm{~h}(\mathrm{Fig} .4 \mathrm{~b})$.

To investigate the specificity of the AP-1 complex, supershift experiments were carried out by adding antibodies against c-Jun, JunB, JunD, c-Fos and ATF2 to the nuclear extracts from IEC-6 cells exposed heat for $1 \mathrm{~h}$. Protein-antibody recognition can be visualized by a decrease in the mobility of the DNA-protein complex and a diminution of the AP-1 complex. Fig. 5a implies that the AP-1 complex is likely to consist of c-Jun and ATF2. However, the hysteretic bands were too vague to confirm this postulation and we could not get better results. Then, western blot analysis was conducted to identify the contributing family members. We found that heat stress did induce the phosphorylation of c-Jun and ATF2 (Fig. 5b). What's more, both c-Jun and ATF2 followed similar kinetic profiles compared with that observed for AP-1(Fig. 4b). Taparowsky et al. found that ATF2 and c-

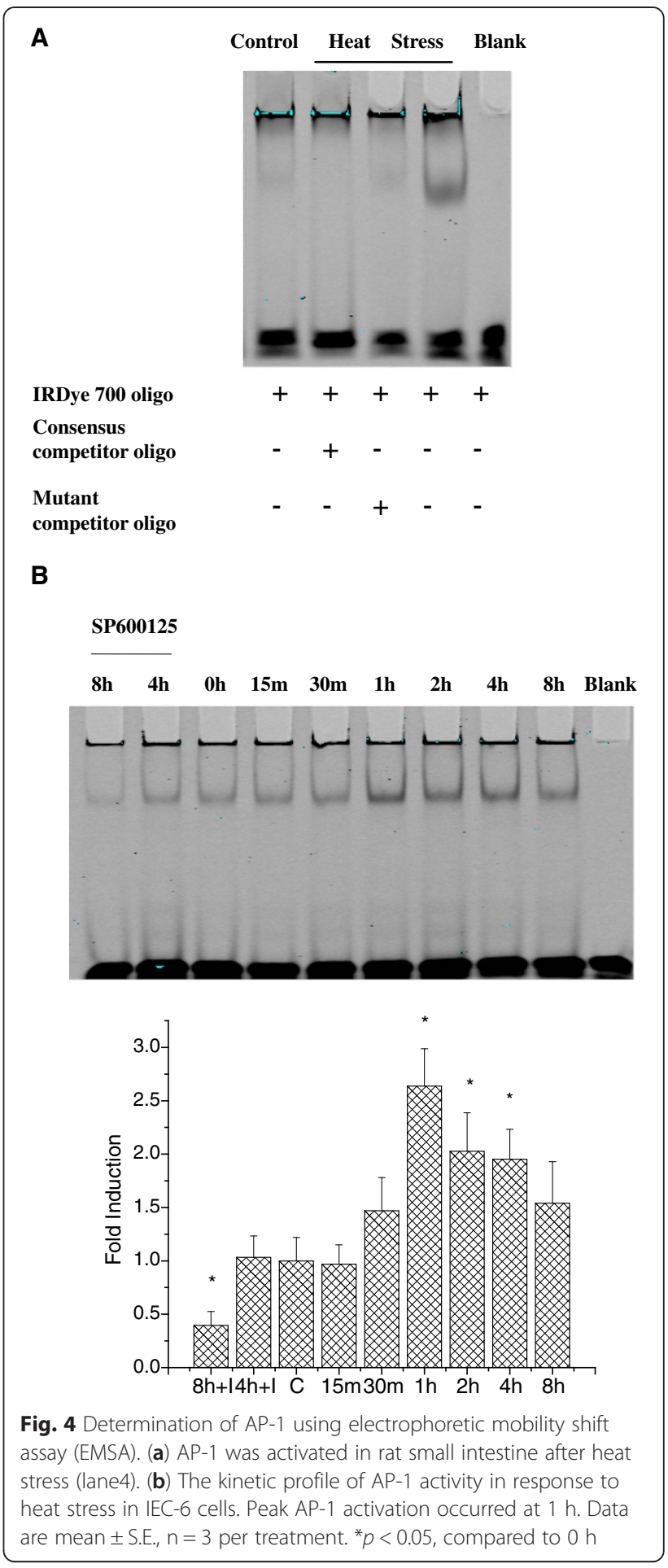

Jun mutually regulate each other to function in the stress response mainly through altering the dynamics of subcellular localization and positively impacting transcriptional activity [20].

The involvement of AP-1 activation in our heat-stress models prompted us to ask whether the JNK pathway might also be involved. To test this hypothesis, western 


\section{A}

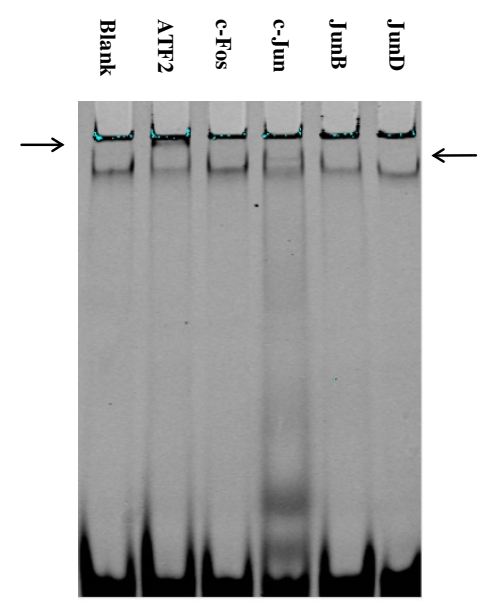

B
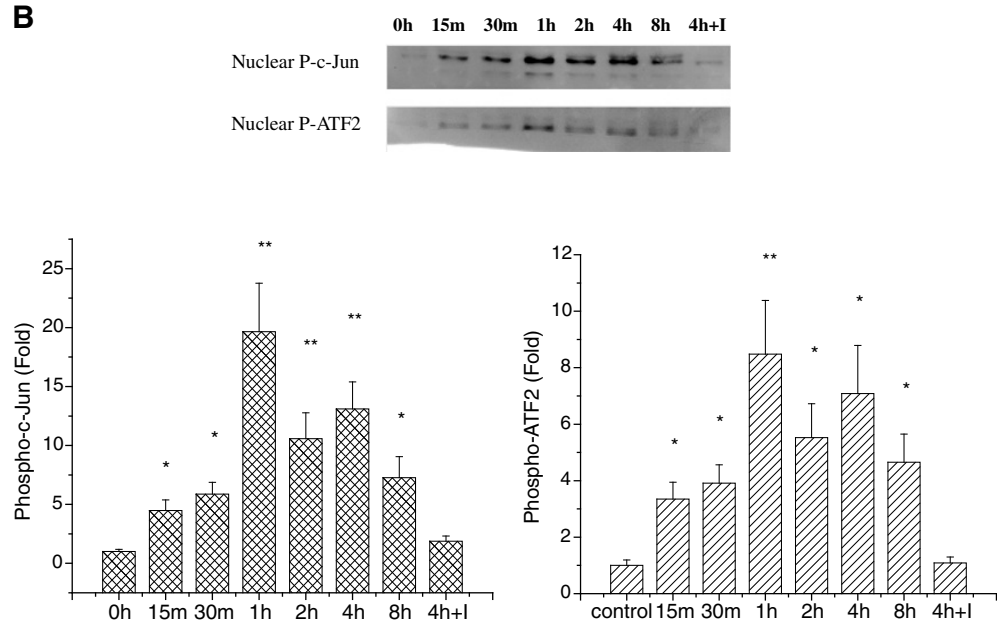

Fig. 5 (a) EMSA Supershift was conducted to identify the contributing family members. Lane 2 and lane 4 showed that the AP-1 complex might be composed of ATF2 and c-Jun (indicated by arrows). Western blotting was performed to identify the specific members (b). Both c-Jun and ATF2 were activated in heat-stress groups and got their highest phosphorylation level after $1 \mathrm{~h}$ treatment. Data are mean \pm S.E., $\mathrm{n}=6$ per treatment. ${ }^{*} p<0.05$, compared to control group, ${ }^{* *} p<0.01$, compared to control group. $4 \mathrm{~h}+\mathrm{l}$ : cells pretreated with JNK inhibitor SP600125 and exposed to heat for $4 \mathrm{~h}$

blot analysis of JNK phosphorylation was performed using the cytoplasmic extract from rat small intestine and IEC- 6 cells. In all three segments of small intestine, heat stress was found to significantly increase JNK phosphorylation in contrast with the control group (Fig. 6a). In IEC-6 cells, JNK phosphorylation was also increased. This effect reached a maximum at $4 \mathrm{~h}$ and lasted for several hours, and was reversible by the addition of JNK inhibitor SP600125 (Fig. 6b). As the main protein upstream of AP-1, JNK is activated first, leading to the phosphorylation of pre-existing c-Jun and ATF2 proteins [21]. To investigate whether JNK inhibition influences the activation of AP- 1 during heat stress, IEC- 6 cells were subjected to heat combined with SP600125. Fig. 4b and Fig. $5 \mathrm{~b}$ show that AP-1 activity is significantly attenuated by the JNK inhibitor SP600125.

\section{Assessment of NF-KB by EMSA and Western blot}

It is widely known that rather than being a mediator of the immune response, NF- $k B$ more generally represents a regulator of stress responses [22]. NF-kB activity can be induced by various stressors including hyperglycemia, hyperthermia, hyperosmotic shock, reactive oxygen species, ischemia/reperfusion, and irradiation. Electrophoretic mobility shift assays were conducted towards transcription factor NF- $\mathrm{kB}$. To our surprise, NF- $\mathrm{kB}$ activation in both rats and IEC-6 cells was not observed (Additional file 1: Figure S1). To confirm this result, we investigated main proteins related to the NF- $\mathrm{KB}$ signaling pathway by western-blot. Exposing rats and IEC-6 cells to hyperthermia did not induce significant phosphorylation of P50 and P65, compared with respective control groups (Additional file 1: Figure S2). Our result 


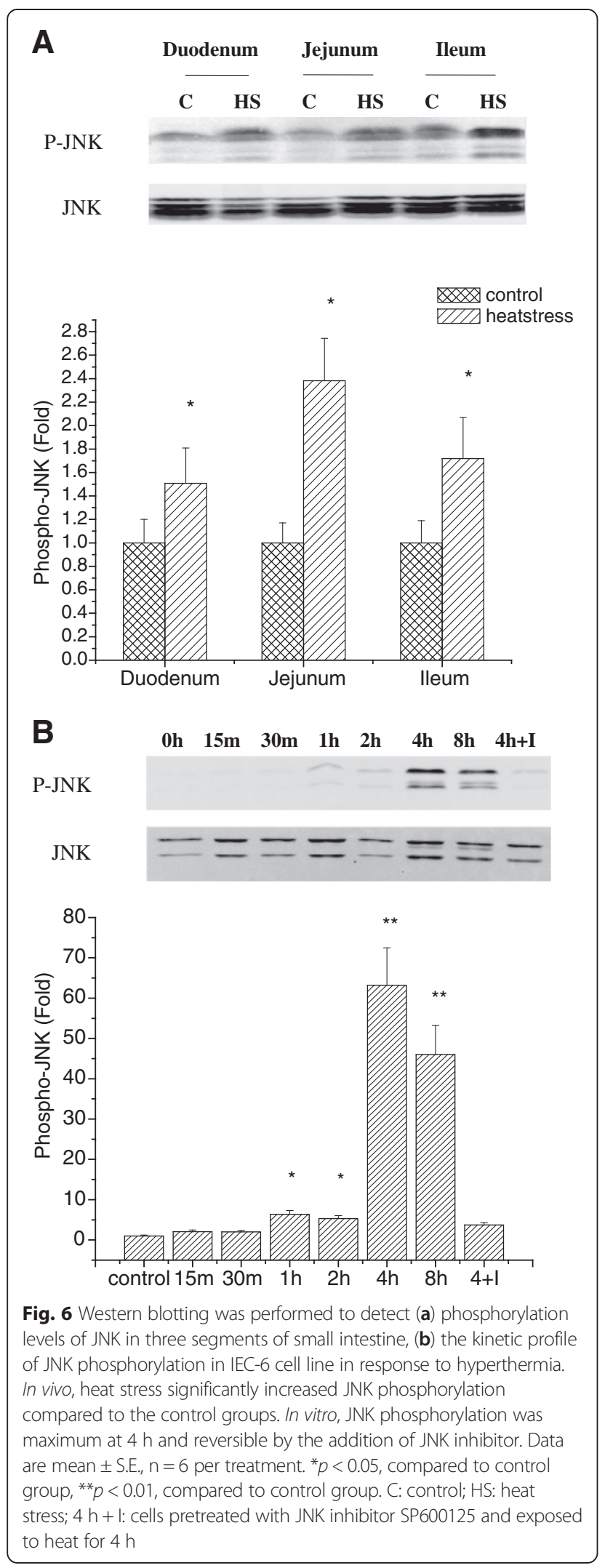

was not consistent with previous report [23], in which hyperthermia enhanced the transcriptional activity of both AP-1 and NF- $\mathrm{kB}$ in PMA/ionomycin treated T cells. Although Ap-1 activity was more rubost in this model, NF- $\mathrm{kB}$ was obviously activated in the presence of heat stress. It's not clear why there was a lack of NF- $\mathrm{kB}$ activation in our models. It may be related to the specificity of both stimulus and cell type. Karin had pointed out that not all cell types responded equally to a given stimulus, and that not every stimulus could activate NF$\mathrm{\kappa B}$ in every cell type examined [24]. On the other hand, it's reported that thermal stress could alter metabolic processes impacting upon intracellular oxidation-reduction status and thereby inhibit the activity of NF- $\mathrm{kB}$ [25]. Our published microarray analysis data had shown that many genes related to oxidation-reduction and metabolism pathways did differently express in response to heat stress [3].

In summary, we have demonstrated that the transcription factor AP-1 (primarily its c-Jun and ATF-2 components) can be activated in rat small intestine and IEC- 6 cells exposed to heat stress, and that the JNK signaling pathway is also involved in this response. However, it remains to be established whether activation of c-Jun/ ATF2 leads to an enhanced level or activity of the genes identified by DNA microarray. Also, the mechanism of NF- $\kappa B$ inactivation needs more in-depth investigations.

\section{Conclusion}

Ap- 1 was activated in rat small intestine and IEC- 6 cells when exposed to heat stress. It is likely to play an important role in regulating gene transcription in these models.

\section{Additional file}

Additional file 1: Figure S1. Electrophoretic mobility shift assay for $\mathrm{NF}-\mathrm{KB}$ in vivo (A) and in vitro (B). NF-KB activation was not observed in both rat small intestine and IEC-6 cells. Figure $\mathbf{S 2}$. Western blotting was performed to detect nuclear p65 and p50 phosphorylation levels in vivo (A) and in vitro (B). There were no significant differences. Data are mean \pm S.E., $n=6$ per treatment. C: control; HS: heat stress.

\section{Competing interests}

The authors have declared that no competing interest exists.

\section{Authors' contributions}

$\mathrm{HZ}$ and $\mathrm{YZ}$ contributed with the study design, molecular biology experiments, data analyses, and manuscript preparation. TL and CW were responsible for animal handling and the histopathological investigation. $\mathrm{XL}$ and $\mathrm{ZG}$ conducted cell culture and treatment. $\mathrm{XH}, \mathrm{L} J$ and $\mathrm{FL}$ participated in the design, coordinated the study and revised the manuscript. All authors read and approved the final manuscript. 


\section{Acknowledgments}

This work was supported by grants from National Natural Science Foundation of China (No. 31272478), National Twelve-Five Technological Supported Plan of China (2013BAD10B04), Ministry of Agriculture, Importation and Development of High-Caliber Talents Project of Beijing Municipal Institutions(CIT\&TCD20130324). We are thankful for the help from the members of CAU-BUA TCVM teaching \& research team.

\section{Author details}

${ }^{1}$ Beijing Key Laboratory for Dairy Cow Nutrition, Beijing University of Agriculture, No. 7, Beinong Road, Changping District, Beijing 102206, P. R. China. ${ }^{2}$ TCVM Laboratory, College of Veterinary Medicine, China Agricultural University, Beijing 100193, China.

Received: 13 August 2014 Accepted: 29 June 2015

Published online: 11 July 2015

\section{References}

1. Lindquist S. The heat-shock response. Ann Rev Biochem. 1986;55:1151-91.

2. Lambert GP, Gisolfi CV, Berg DJ, Moseley PL, Oberley LW, Kregel KC. Selected contribution: hyperthermia-induced intestinal permeability and the role of oxidative and nitrosative stress. J Appl Physiol. 2002;92(4):1750-61.

3. Lu A, Wang H, Hou X, Li H, Cheng G, Wang N, et al. Microarray analysis of gene expression profiles of rat small intestine in response to heat stress. J Biomol Screen. 2011;16(6):655-67.

4. Yu J, Yin P, Yin J, Liu F, Zhu X, Cheng G, et al. Involvement of ERK12 signalling and growth-related molecules expression in response to heat stress-induced damage in rat jejunum and IEC-6 cells. Int J Hyperthermia. 2010;26:538-55.

5. Karin M, Lin A. NF-kB at the crossroad of life and death. Nat Immunol. 2002:3:221-7.

6. Shaulian E, Karin M. AP-1 in cell proliferation and survival. Oncogene. 2001:20:2390-400

7. Mercurio F, Manning AM. NF-kB as a primary regulator of the stress response. Oncogene. 1999;18:6163-71.

8. Scheidereit C. IkappaB kinase complexes: gateways to NF-kappaB activation and transcription. Oncogene. 2006:25(51):6685-705.

9. Dam HV, Castellazzi M. Distinct roles of Jun:Fos and Jun:ATF dimers in oncogenesis. Oncogene. 2001;20:2453-64.

10. Morooka H, Force T, Bonventre JV, Pombo CM, Kyriakis JM. Ischemia and reperfusion enhance ATF-2 and c-Jun binding to CAMP response elements and to an AP-1 binding site from the c-Jun promoter. J Biol Chem. 1995:270:30084-92.

11. Cowan KJ. Mitogen-activated protein kinases: new signaling pathways functioning in cellular responses to environmental stress. J Exp Biol. 2003:206(7):1107-15.

12. Cargnello M, Roux PP. Activation and function of the MAPKs and their substrates, the MAPK-activated protein kinases. Microbiol Mol Biol Rev. 2011;75(1):50-83.

13. Raman $\mathrm{M}$, Chen W, Cobb MH. Differential regulation and properties of MAPKs. Oncogene. 2007;26(22):3100-12.

14. Liu J, Lin A. Wiring the cell signaling circuitry by the NF-kappa B and JNK1 crosstalk and its applications in human diseases. Oncogene. 2007:26(22):3267-78

15. Yu J, Yin P, Liu F, Cheng G, Guo K, Lu A, et al. Effect of heat stress on the porcine small intestine: a morphological and gene expression study. Comp Biochem Physiol A Mol Integr Physiol. 2010;156(1):119-28.

16. Yu J, Liu F, Yin P, Zhu X, Cheng G, Wang N, et al. Integrating miRNA and mRNA expression profiles in response to heat stress-induced injury in rat small intestine. Functional \& integrative genomics. 2011;11(2):203-13.

17. Shen L, Su L, Turner JR. Mechanisms and functional implications of intestinal barrier defects. Dig Dis. 2009;27(4):443-9.

18. Hinnebusch BF, Ma Q, Henderson FW, Siddique A, Archer SY, Hodin RA. Enterocyte response to ischemia is dependent on differentiation state. J Gastrointest Surg. 2002;6:403-9.

19. Kühl NM, Rensing L. Heat shock effects on cell cycle progression. Cell Mol Life Sci. 2000:57:450-63.

20. Liu H, Hu C, Deng X, Shyu YJ, Li JJ, Taparowsky EJ. Mutual regulation of c-Jun and ATF2 by transcriptional activation and subcellular localization. EMBO J. 2006;25:1058-69.
21. Ribas VT, Arruda-Carvalho M, Linden R, Chiarini LB. Early c-Jun N-terminal kinase-dependent phosphorylation of activating transcription factor-2 is associated with degeneration of retinal ganglion cells. Neuroscience. 2011;180:64-74.

22. Pahl HL. activators and target genes of Rel/NF-KB transcription factors. Oncogene. 1999:18:6853-66.

23. Cippitelli M, Fionda C, Di Bona D, Piccoli M, Frati L, Santoni A. Hyperthermia Enhances CD95-Ligand Gene Expression in T Lymphocytes. J Immunol. 2004;174(1):223-32.

24. Karin M. How NF-KB is activated the role of the IkB kinase(IKK) complex. Oncogene. 1999;18:6867-74.

25. Mattson D, Bradbury CM, Bisht KS, Curry HA, Spitz DR, Gius D. Heat shock and the activation of AP-1 and inhibition of NF-kappa B DNA-binding activity: possible role of intracellular redox status. Int J Hyperthermia. 2004;20(2):224-33.

\section{Submit your next manuscript to BioMed Central and take full advantage of:}

- Convenient online submission

- Thorough peer review

- No space constraints or color figure charges

- Immediate publication on acceptance

- Inclusion in PubMed, CAS, Scopus and Google Scholar

- Research which is freely available for redistribution

Submit your manuscript at www.biomedcentral.com/submit 